\title{
BMJ Open Relationship between sociodemographic factors and selection into UK postgraduate medical training programmes: a national cohort study
}

\author{
Ben Kumwenda, ${ }^{1}$ Jennifer A Cleland, ${ }^{1}$ Gordon J Prescott, ${ }^{2}$ Kim Walker, ${ }^{3}$ \\ Peter W Johnston ${ }^{4}$
}

To cite: Kumwenda B, Cleland JA, Prescott GJ, et al. Relationship between sociodemographic factors and selection into UK postgraduate medical training programmes: a national cohort study. BMJ Open 2018;8:e21329. doi:10.1136/ bmjopen-2017-021329

- Prepublication history for this paper is available online. To view these files, please visit the journal online (http://dx.doi. org/10.1136/bmjopen-2017021329).

Received 21 December 2017 Revised 9 May 2018 Accepted 25 May 2018
Check for updates

${ }^{1}$ Centre for Healthcare Education Research and Innovation (CHERI), School of Medicine,

Medical Sciences and Nutrition, University of Aberdeen,

Aberdeen, UK

${ }^{2}$ Medical Statistics Team, School of Medicine, Medical Sciences \& Nutrition, University of Aberdeen, Aberdeen, UK

${ }^{3} \mathrm{NHS}$ Grampian, NHS Education for Scotland and UK Foundation Programme, Aberdeen, UK

${ }^{4}$ NHS Education for Scotland,

Scotland Deanery, Aberdeen, UK

Correspondence to

Ben Kumwenda;

r01bk15@abdn.ac.uk

\section{ABSTRACT}

Introduction Knowledge about allocation of doctors into postgraduate training programmes is essential in terms of workforce planning, transparency and equity issues. However, this is a rarely examined topic. To address this gap in the literature, the current study examines the relationships between applicants' sociodemographic characteristics and outcomes on the UK Foundation Training selection process.

Methods A longitudinal, cohort study of trainees who applied for the first stage of UK postgraduate medical training in 2013-2014. We used UK Medical Education Database (UKMED) to access linked data from different sources, including medical school admissions, assessments and postgraduate training. Multivariable ordinal regression analyses were used to predict the odds of applicants being allocated to their preferred foundation schools.

Results Applicants allocated to their first-choice foundation school scored on average a quarter of an SD above the average of all applicants in the sample. After adjusting for Foundation Training application score, no statistically significant effects were observed for gender, socioeconomic status (as determined by income support) or whether applicants entered medical school as graduates or not. Ethnicity and place of medical qualification were strong predictors of allocation to preferred foundation school. Applicants who graduated from medical schools in Wales, Scotland and Northern Ireland were 1.17 times, 3.33 times and 12.64 times (respectively), the odds of applicants who graduated from a medical school in England to be allocated to a foundation school of their choice.

Conclusions The data provide supportive evidence for the fairness of the allocation process but highlight some interesting findings relating to 'push-pull' factors in medical careers decision-making. These findings should be considered when designing postgraduate training policy.

\section{BACKGROUND}

Efforts to minimise the barriers against entry into medicine have had mixed success, despite policy and investment drives. ${ }^{1-4}$ In the
Strengths and limitations of this study

- This is one of the first studies to use linked individual-level data from the UK Medical Education Database, enabling longitudinal analysis and comparisons across previously discreet datasets.

- A large-scale study that focuses on the time of exit from medical school and selection to the next stage of postgraduate medical training in the UK.

- The sample did not include international medical graduates or students who sat an aptitude test other than the UK Clinical Aptitude Test at the time of applying to medical school.

- We did not examine outcomes by individual medical schools because of non-convergence issues with statistics models.

last 30 years, the UK medical student body has become increasingly diverse in terms of gender, ethnicity and age, but not in terms of socioeconomic background (an individual's or family's economic and social position in relation to others, based on income, education and occupation ${ }^{5}$ ). Indeed, a recent independent review concluded that: 'Medicine has a long way to go when it comes to making access fairer, diversifying its workforce and raising social mobility. ${ }^{6}$

Much research has examined the barriers associated with selection into medical school for those from lower socioeconomic groups. ${ }^{78}$ While getting a medical school place is the first hurdle in medical education and training, those who successfully complete medical school then face many other selection challenges for postgraduate education and training. The precise nature of these differ by context-in some countries, like the UK and Australia, medical graduates apply for early-stage training programmes of 1 or 2 years, then apply for specialty training. In other countries, such as the USA and Japan, 
those graduating from medical schools apply directly for residency (specialty) training.

Yet, relatively little is known about the relationship between individual characteristics, such as socioeconomic background and outcomes on selection processes for postgraduate medical training. The few studies addressing this tend to focus on selection into specialty training, and relate to the ethnic differences in the academic attainment of doctors, ${ }^{9} 10$ gender or country of primary medical qualification. ${ }^{11} 12$ To the best of our knowledge, there has been no research looking at the relationships between individual characteristics and allocation into the first stage of postgraduate medical education in the UK, Foundation Training. This is a generic 2-year training programme which bridges the gap between medical school and being eligible to apply for specialty (including general practice/family medicine) training. Successful completion of the first year of Foundation Training (FY1) is needed for full medical registration. The process of assigning applicants to positions is based on a matching algorithm between allocation score and applicant choice. Applicants with the highest ranking are most likely to receive their first choice of training post. The UK Foundation Programme Office (UKFPO) reports that around $20 \%$ of applicants do not get allocated to their first-choice foundation school, and 12\% of applicants in 2016 were allocated to a foundation school that was lower than their fifth preference. ${ }^{13}$

In 2009, the Department of Health in England commissioned a review of selection to the Foundation Programme. The aim of this review was to recommend a reliable, robust, valid, feasible and sustainable method for allocation which would minimise the risk of successful legal challenge. ${ }^{14}$ A new tool, the situational judgement test (SJT), was introduced, replacing the old 'white space' questions on an online application form. Scores from the SJTs and the standardised Educational Performance Measure (EPM) (see methods section) are added together to form the Foundation Training application score.

The purpose of this study was to investigate the relationship between individual characteristics and allocation to Foundation Training. In seeking to understand the social equity and fairness of the postgraduate selection process, the present study tests the hypothesis that persistent inequalities continue to exist even after non-traditional students have gained access into medical school. Since students from low socioeconomic backgrounds face financial, social and cultural barriers to higher education in general,${ }^{15}$ we envisage that those who enter medicine face similar challenges. For example, because of the extra financial burden, students from less affluent backgrounds may opt out of intercalated degrees or medical electives abroad despite these being factors that contribute towards attainment at medical school and future progress. ${ }^{16-18}$ Our aim, therefore, was to determine if the allocation of trainees to their preferred foundation schools differs on the basis of socioeconomic class or other individual characteristics.

\section{METHODS}

This is a longitudinal, cohort study of students who entered UK medical schools in 2007 and 2008, and who commenced their postgraduate training in 2013 and 2014. We used linked individual-level data from the UK Medical Education Database (UKMED: https://www. ukmed.ac.uk/) as the basis for this study. UKMED allows the analysis of data from a number of sources, including medical school admissions, assessment and postgraduate training. UKMED also contains demographic data such as age, gender, ethnicity, and whether the individual was a school leaver or graduate at the time of entry to medical school. Variables relating to socioeconomic status are also available. These have been used widely in previous UK research examining factors that influence educational achievement of different types of pupils, particularly in terms of widening participation. ${ }^{19-22}$ They included: parental occupation (derived from National Statistics Socioeconomic Classification); entitlement to free school meals (FSM); income support; participation of local areas (POLAR), which is an indicator of the participation of young people in higher education by UK geographical area; type of school (state funded or independent) and parental education. We also included place of medical graduation (UK country: England, Scotland, Wales and Northern Ireland) into the analysis.

Twenty-one foundation schools offered postgraduate training at the time of the study. Applicants rank their choice of the foundation school in order of preference (1-21), and allocation to Foundation training (offers) is based on an algorithm of the Foundation Training application score. This score is the sum of the overall medical school performance (EPM) and performance on the SJT. The EPM and SJT have a maximum score of 100 points, and an applicant's score out of 100 is their application score. The SJT is worth up to 50 points. ${ }^{23}$ The EPM is also worth a maximum of 50 points and comprises three parts: medical school performance (34-43), additional degrees, $0-5$ and other educational achievements such as publications and prizes, $0-2$. All students are ranked according to medical school performance and are then grouped into deciles with those in the lowest decile receiving 34 points and the highest decile receiving 43 points. This could be thought of as a baseline medical school performance of 33 points awarded to all students with 1-10 additional points corresponding to each decile of performance. Although the EPM and SJT together have a maximum score of 100 points, and an applicant's score out of 100 is their UKFPO application score. All applicants who have a satisfactory SJT are offered a foundation place. All things being equal, high performing applicants would be offered a place at a foundation school that was high on their preference list, and lower scoring applicants would be offered places at a foundation school that was lower in their order of preference. As a number of applicants can withdraw from the Foundation programme for various reasons, this sample contain only those who commenced Foundation Training in 2013 and 2014. 
The Foundation Training (UKFP) application scores were not normally distributed. For that reason, we converted the application score into a 'percentile rank' to help us determine the individual ranking in relation to others within the sample. This allowed us to evaluate the effect of a change of one decile group. We used Kruskal-Wallis, and where necessary, Mann-Whitney U tests to compare the scores across independent groups. We also transformed the rank of the foundation school allocated into an ordinal dependent variable. The following values were assigned: (1) for being allocated to the applicant's first-choice foundation school; (2) for allocation to a second or third choice and (3) for allocation to a foundation school outside the applicant's top three choices. $\mathrm{X}^{2}$ tests were used to examine the relationship between applicants' sociodemographic characteristics and the dependent variable, choice of foundation school. Standardised $\mathrm{z}$ scores for the Foundation Training application scores were calculated to permit comparison across the ordinal dependent variable. Finally, a multivariable ordinal logistic regression was used to estimate the effect of several factors against the outcome measure. The variable, UK country of medical qualification, was also fitted in the models to take account of various unmeasured characteristics associated with regional variation across the four UK countries which are not otherwise represented in the models. Its inclusion had the effect of greatly improving the model's predictive power based on $\log$ likelihoods. All the data analyses were done using IBM SPSS Statistics for Windows, V.24 (IBM).

\section{Patient and public involvement}

Patients and the general public were not involved in the design of this research. Ethics approval was not required because the focus of this study was a secondary analysis of anonymised data.

\section{RESULTS}

The UKMED database comprises 13763 students who sat the UK Clinical Aptitude Test (UKCAT) of 2006-2008, commenced their medical studies in 2007-2009 and applied for postgraduate training in 2012 and 2014. For this study, the graduating cohort of $2012(\mathrm{n}=3702)$ was removed from the sample because the SJT component of the UKFP selection process was piloted that year, and did not contribute towards the Foundation Training application score. In addition, nearly $11.6 \%(\mathrm{n}=1594)$ students were excluded from the analysis because they were on the Academic Foundation Programme (AFP), which has a different, and completely separate, selection process. Applicants to the AFP are nominated by their graduating medical school, and recruitment is coordinated at regional level and takes place nearly 6 months before the national application process.

Thus, the final eligible sample included 8467 Foundation Programme doctors (applicants who had accepted a place and commenced their training in 2013 or 2014).
Table 1 displays their sociodemographic characteristics in relation to application scores. The table also shows the numbers and percentages of doctors and the preference category of their allocated foundation schools. Frequency data shows that $71.3 \%$ of doctors were allocated to their first-choice foundation school; $15.0 \%$ to their second or third choice and $13.7 \%$ to a foundation school that was not one of their top three choices.

$\mathrm{X}^{2}$ tests showed statistically significant associations between certain sociodemographic characteristics and category of allocation to foundation school. Female applicants were significantly more likely $(\mathrm{p}<0.001)$ than male applicants to be allocated to a higher choice foundation school ( $73 \%$ vs $69 \%$ first choice). Students who attended state-funded (high) schools, and those who entered medical school as graduates were significantly more likely to be allocated to a higher choice foundation school than students who attended privately funded school $(\mathrm{p}<0.01)$ ( $74 \%$ vs $67 \%$ first choice), or those who came into medical schools as typical school leavers vs graduates $(\mathrm{p}=0.016)(76 \%$ vs $70 \%$ first choice). A significantly larger proportion of applicants coming from families that were at some point recipients of income support $(p=0.028)$, and those entitled to FSM $(p=0.043)$ did not get a place in a higher choice foundation school $(65 \%$ vs $73 \%$ and $70 \%$ vs $73 \%$ first choice, respectively). Applicants from white ethnic backgrounds were significantly more likely to be allocated to a higher choice foundation school than black or Asian applicants $(\mathrm{p}<0.001) \quad(79 \%$ vs $47 \%$ and $56 \%$ first choice, respectively). The majority $(93 \%)$ of non-Caucasian applicants had graduated from medical schools in England (93\%), and nearly the same proportion accepted a Foundation Training post (90\%) at an English foundation school.

The z-score of the Foundation Training application score for the first-choice group was 0.25 indicating that those applicants who were allocated to a foundation school of their first choice scored on average a quarter of a standard deviation above the average of all applicants in the sample.

Although differences in allocation to preferred school would be expected to reflect the individuals' selection scores (table 2), other sociodemographic factors might also be influential. Therefore, we performed an ordinal regression analysis to determine whether the odds of applicants getting allocated to a preferred foundation school differed significantly for different groups. Variables that were not significantly associated with allocation to foundation school during univariate analysis, using a conservative $\mathrm{p}<0.10$, were removed from the regression models. Where two or more measured independent variables appeared to measure the same constraint, we only included the variable which we thought contributed more to the explanation of the dependent variable. For example, since a majority of the students on FSM also come from families that are a recipient of income support, the FSM variable was dropped from the regression models. Application scores were divided into deciles 


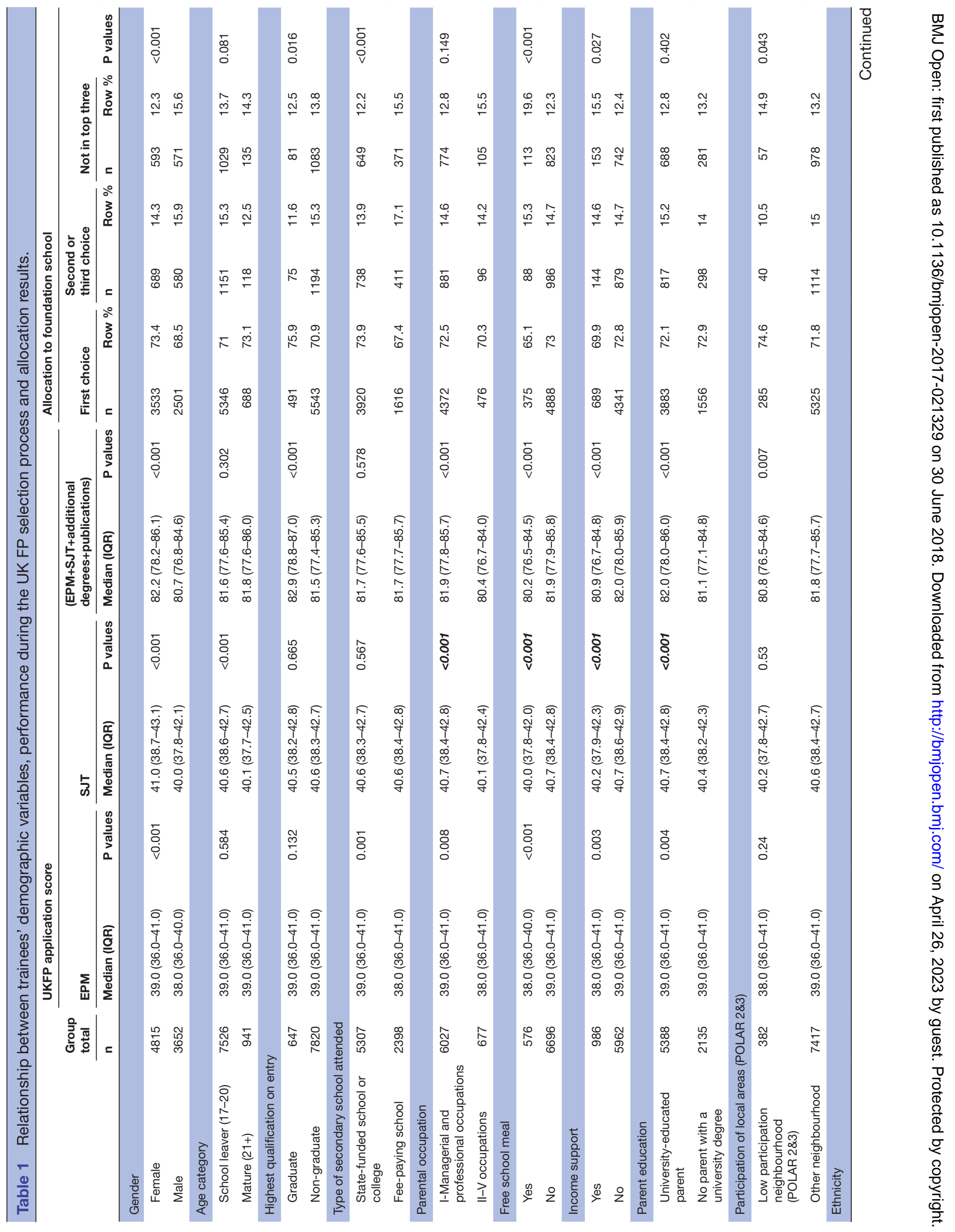




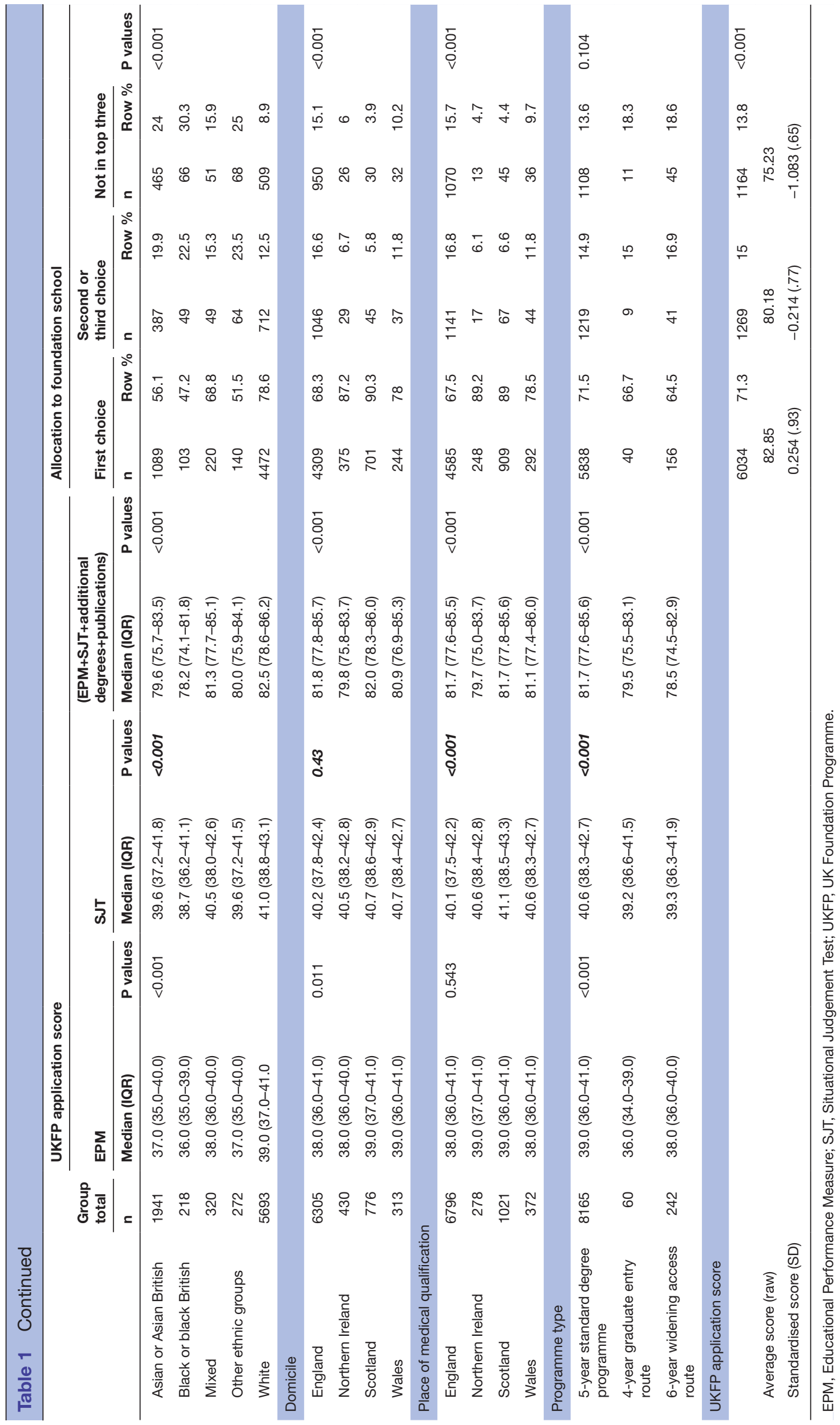

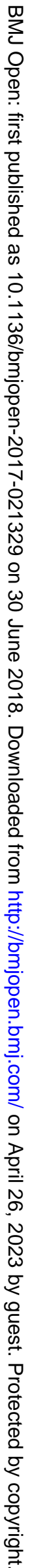


Table 2 Selection scores across the three allocation groups

\begin{tabular}{|c|c|c|c|c|c|c|c|}
\hline & \multirow[b]{2}{*}{$\mathbf{N}(\%)$} & \multicolumn{3}{|c|}{ EPM decile * } & \multicolumn{3}{|l|}{ SJT } \\
\hline & & Mean & SD & P values & Mean & SD & $\mathbf{P}$ values \\
\hline First choice & 6034 (71.3) & 39.16 & 2.67 & $<0.001$ & 41.05 & 3.18 & $<0.001$ \\
\hline Outside top 3 & $1164(13.7)$ & 36.07 & 1.91 & & 37.35 & 3.17 & \\
\hline
\end{tabular}

*Excludes points accrued from other sources, that is, additional degrees, publications, presentations and prizes. EPM, Educational Performance Measure; SJT, situational judgement Test.

according to percentile rank we had calculated to determine individual's score relative to others in the sample. Thus, applicants in the highest (90th-100th percentile) rank were assigned a value of 1 , those in the second highest (80th-89th percentile) rank were assigned a value of 2 and so on until those in the bottom $(0-10$ th percentile) were assigned a value of 10 . We could then evaluate the effect of a change of one decile group.

The results of multivariate ordinal regression are shown in table 3. Three separate models were fitted; model 1 without controlling for the effect of application score, model 2 after accounting for the effect of the application score and model 3 after accounting for the effect of the application score and the allocated foundation school competition ratio. The ordinal regression is an extension of the binary logistic regression. The ORs represent each of the cut-off points, and the odds are expressed as a single cumulative OR for each group. The $\beta$ results in table 3 are log ORs. Negative values represent a reduction in the odds of being allocated a preferred choice. Positive values represent an increase in odds of being allocated a preferred choice. As log ORs are difficult to interpret, we present the OR, the exponential of $\beta$, in the text. In model 3, for every unit increase of the Foundation Training 'decile' application score rank ( 1 best, 10 worst), the odds of an applicant getting allocated to a foundation school they had ranked higher in their order of preference decreased, as it was multiplied by a factor of $0.58(\beta=-0.551, \mathrm{p}<0.001)$. In lay terms, after considering other factors, the lower an individual's application score, the less likely they are to get their preferred choices of foundation school.

The models confirmed that there are significant effects in allocation to preferred school related to certain sociodemographic variables. Notably, model 3 shows that after controlling for the presence of multiple factors, including the application score and the foundation school competition ratio, the following groups had significantly lower odds of being allocated to their higher choice foundation schools: those from non-white ethnic groups; those who attended privately funded (high) school; who came from areas with high proportion of young people in higher education (POLAR); who graduated from an English medical school.

The odds of an applicant of Asian ethnic group to be allocated to a foundation school that they had ranked of higher preference was 0.66 times $(\beta=-0.410, \mathrm{p}<0.001)$ that of a white applicant (just over half the odds). Similarly, given that the other variables in the model are held constant, the odds of a black applicant to be allocated to a foundation school of higher choice in the ranking order of preference were 0.61 times or approximately over half the odds of a white applicant $(\beta=-0.490, \mathrm{p}<0.001)$. Despite obtaining similar application scores, applicants who attended privately funded (high) schools had lower odds, by a factor of 0.77 , compared to those who attended state-funded schools $(\beta-=0.258, \mathrm{p}<0.001)$. The odds for applicants who came from areas of high participation of young people in higher education (POLAR) to be allocated to a foundation school of their preferred choice were 0.66 times $(\beta=-0.413, \mathrm{p}<0.001)$ or $34 \%$ lower than applicants who came from areas of low participation. We also compared places of primary medical qualification by UK country. All other things being equal, the odds of applicants who graduated from medical schools in Wales $(\beta=0.153, \mathrm{p}=0.353)$ Scotland $(\beta=1.172, \mathrm{p}<0.001)$ and Northern Ireland $(\beta=2.537, \mathrm{p}<0.001)$ were 1.17 times, 3.22 times and 12.64 times (respectively), the odds of applicants who graduated from a medical school in England to be allocated to a foundation school of higher preference. After adjusting for Foundation Training application score, no statistically significant effects were observed for gender, socioeconomic status (as determined by income support) or whether applicants entered medical school as graduates, or not.

\section{DISCUSSION}

This large-scale study of two cohorts of applicants for the first stage of postgraduate medical training in the UK provides reassuring data. First, there is a clear relationship between an individual's performance on foundation school selection (their application score), and whether or not they are allocated to their first choice of foundation school. Second, the foundation school selection process does not appear to discriminate against applicants from lower socioeconomic groups. On the other hand, after controlling for the effect of the application scores, our analysis indicated that certain sociodemographic factors-ethnicity, type of (high) school attended, being from an area of high educational participation and (UK) country of medical qualification-are strong predictors of allocation to preferred choices. 


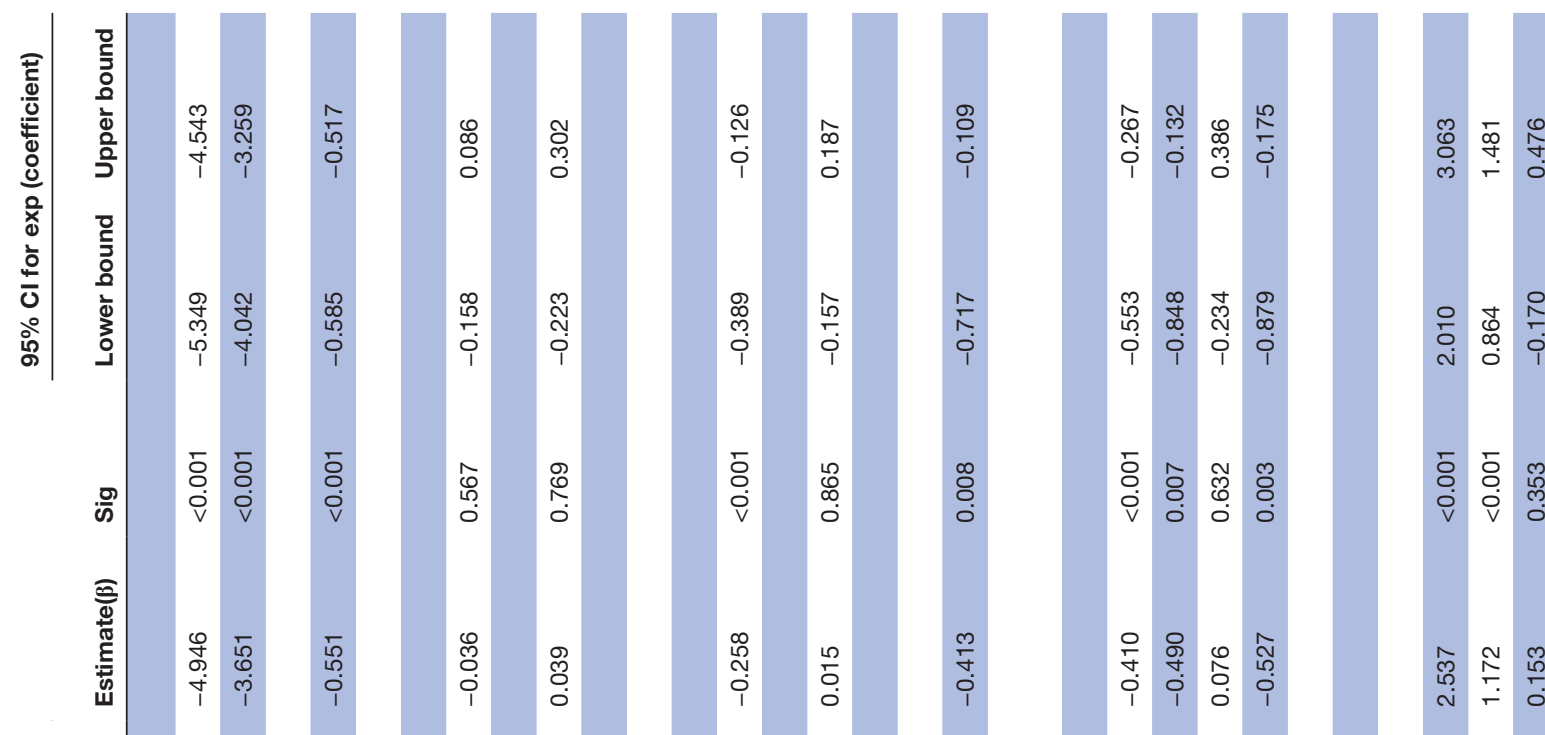

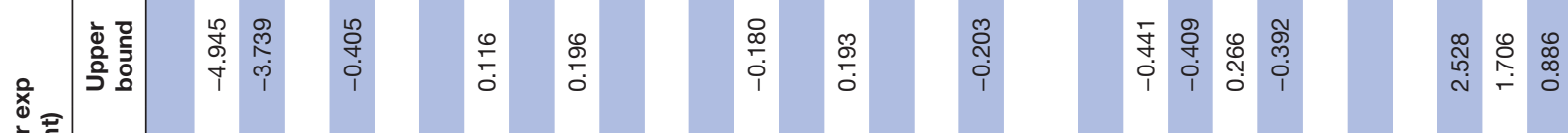

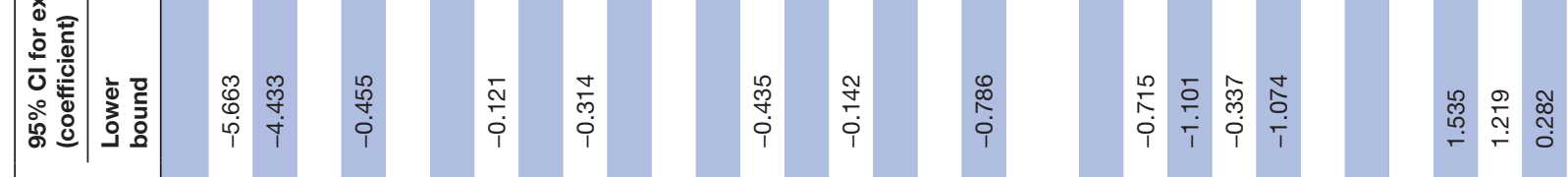

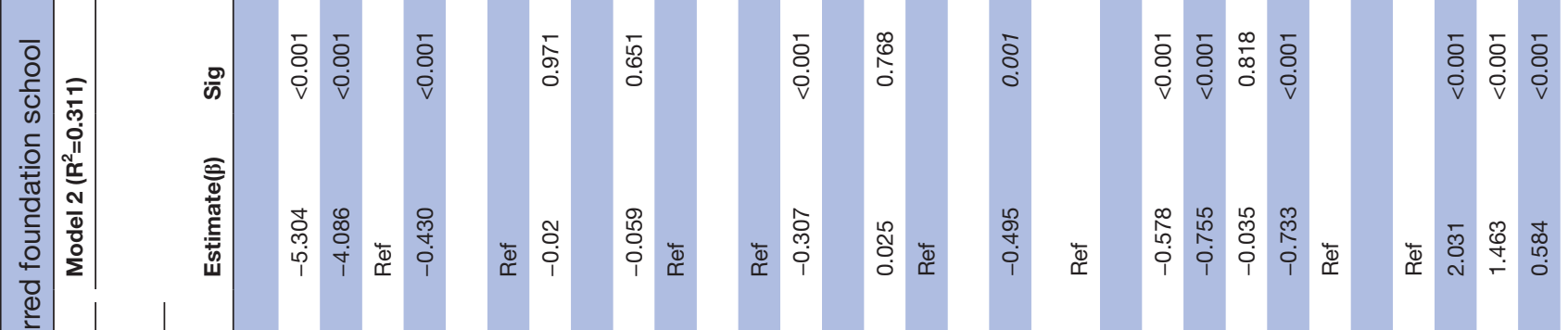

흘

:

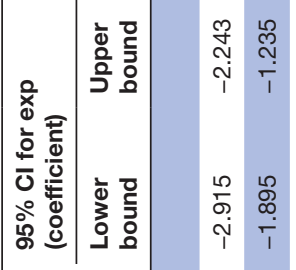

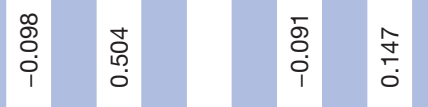
ڤิ

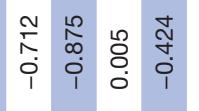

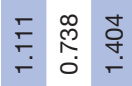
0
0
0
0
0

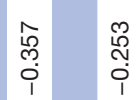

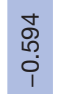

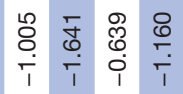

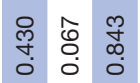
$\overline{0}$
$\overline{0}$

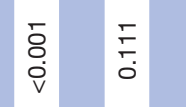

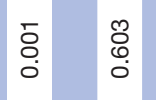

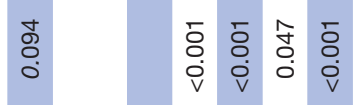
它

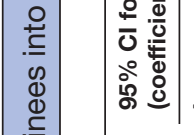

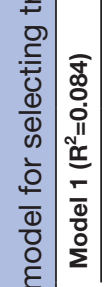

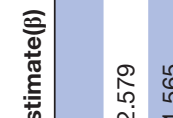

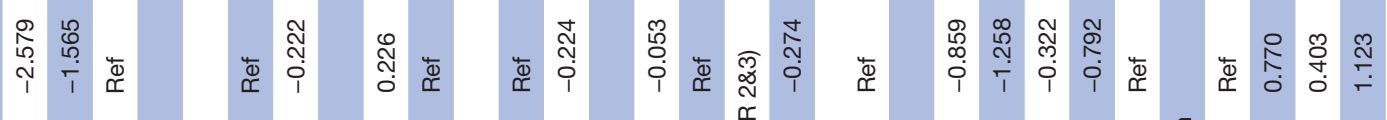

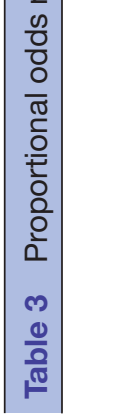

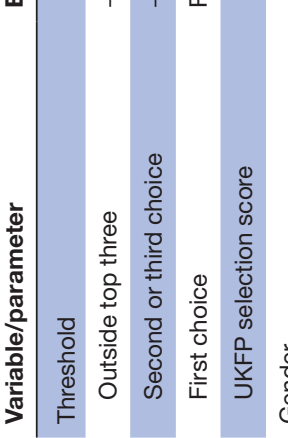
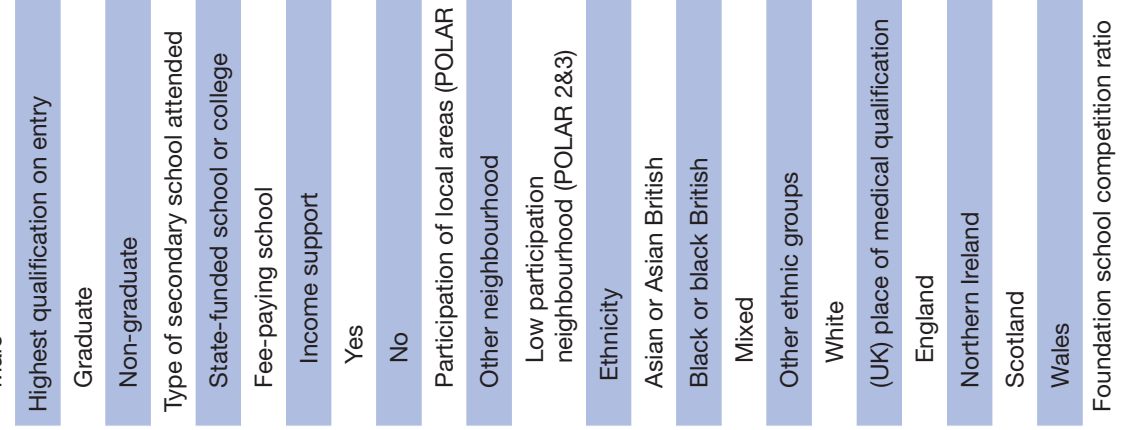

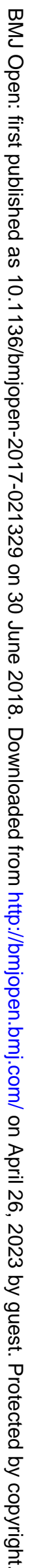




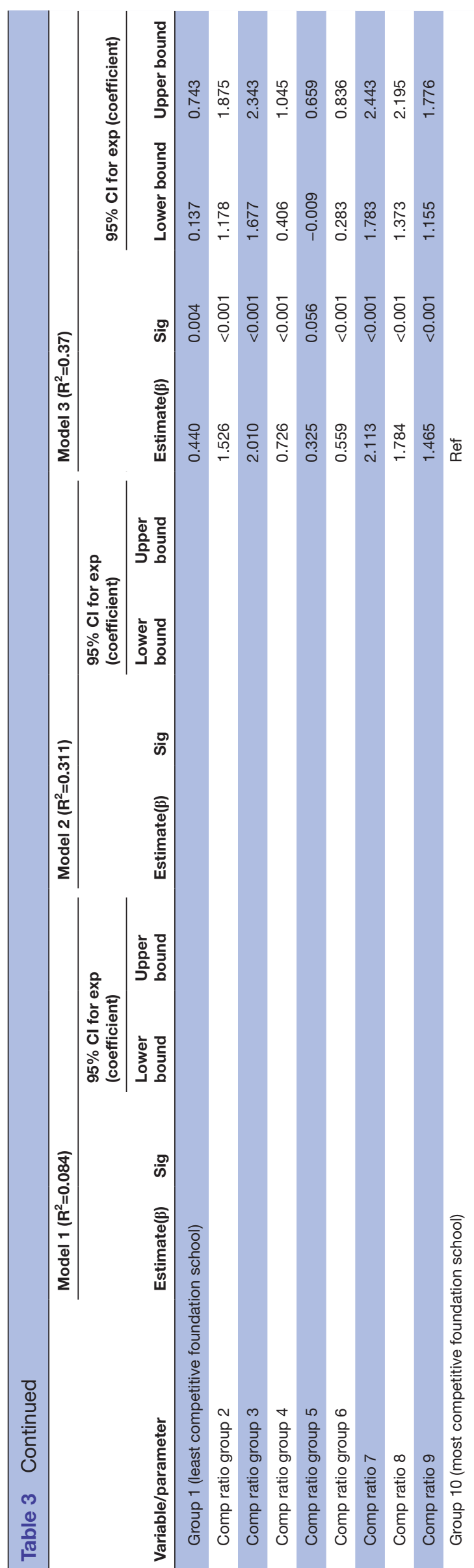

The pattern observed for areas of high educational participation and fee-paying high school appear, on face value, to discriminate against those from higher socioeconomic groups. This seems counter-intuitive given previous research indicates that social class is one of the factors associated with admission to medical school ${ }^{324} 25$ and specialty choice. ${ }^{26-28}$ Several related factors may explain this finding. For example, different foundation schools have differing competition ratios. The 2016 competition ratio, which is the number with first-choice preference divided by the number of training programme places available, was highest in London area (1.49), compared with South of England (1.25), Scotland (1.12), Northern Ireland (0.97), Wales (0.93) and the Rest of England $(0.65) .{ }^{23}$ A large proportion of UK medical schools and medical students are situated around London and the South of England ${ }^{29}$ and many medical students wish to do their Foundation Programme in a familiar region or have the opportunity to access training in the capital. ${ }^{30}$ Related to this, London and the South of England are where much of the UK population is based, and many medical students and early career doctors prefer to train and work nearby their family and friends. ${ }^{31}{ }^{32}$ Finally, applicants from areas of high educational participation and from independent schools-and note there is a strong relationship between these two factors ${ }^{33}{ }^{34}$ may be more likely to apply to highly competitive foundation schools (eg, London and the South of England). Taking these factors as a whole, London and the South of England are very popular places to train and work, and so there is more competition for places. Applicants who put these regions as their top choice(s) are therefore less likely to get their top choice(s). Interestingly, the less competitive foundation schools also have the highest number of 'home applicants', again supporting the suggestion that early career doctors wish to train and work near family and friends. ${ }^{30} 31$

Our finding that those from Black and minority ethnic (BME) backgrounds are less likely to be allocated their first-choice foundation school is consistent with the wider literature on postgraduate training showing that those from BME backgrounds tend to do less well in many different medical examinations. ${ }^{91035}$ However, it is evident that, even after controlling for the effect of the application score and foundation school competition ratio, those from ethnic minorities appear to be disadvantaged. This finding may also be linked with the geographical preferences discussed above because a higher proportion of the UK medical student population from BME backgrounds live in London and the Southeast of England. ${ }^{29}$ It is clear that the marked differences observed in the ethnic profile of medical students across the UK countries also continues into the Foundation Training. Although we have not carried out a 'head-to-head' comparison of diversity across the foundation schools, UK demographic patterns suggest that these differences relate to student/ foundation doctor origin/home (ie, the proportion of BME groups differs across different UK countries and cities). 
The merit of this study is that it is one of the first to use the UKMED database. ${ }^{36-38}$ UKMED links several large datasets together, enabling longitudinal analysis and comparisons across previously discrete datasets. Another merit of the study is it is large scale and focus on the time of exit from medical school and selection to the next stage of postgraduate training in the UK. As with any study, there are limitations. Some of the markers included in the analysis overlap, particularly socioeconomic class, ethnicity and graduating from English medical schools. This is unavoidable given the links between place, poverty and ethnicity in the UK. ${ }^{39}$ The wider literature also shows that there is a link between class and university preferences, ${ }^{41} 42$ and there are hints in the medical education literature that this might also be the case for medical school preferences. ${ }^{43}$ The nature of the data, coupled with the complexities of 'class' in the UK, mean we could not separate out the individual contributions of these intersecting factors on foundation allocation. Our sample did not include international medical graduates, or students who sat an aptitude test other than the UKCAT at the time of applying to medical school. The reason for this is simple: other medical schools' admissions aptitude test data is not yet held by UKMED. However, the UKCAT is sat by $85 \%$ plus of those applying for medical school in the UK (personal communication, UKCAT 29 November 2017) so represents the majority of applicants. We would have liked to examine outcomes by individual medical school rather than just UK country (eg, Scotland, England, etc) given previous research has highlighted that students from different medical schools perform differentially on postgraduate examinations. ${ }^{35}$ We were unable to do so because of non-convergence issues with the statistical models. The UKFP SJT is relatively new but there are already some indicators of its psychometric properties, particularly predictive validity. ${ }^{44}{ }^{45}$ The nature of our study design means we have identified patterns but further, qualitative work is required to explore the reasons for these patterns. Future research could also usefully focus on the next stage of postgraduate training by examining the relationship between allocation to foundation school and later specialty training allocation.

In conclusion, this large-scale study has shown there is a clear relationship between an individual's performance on application to Foundation Programme (their application score), and whether or not they are allocated to their first choice of foundation school. Second, the UKFP allocation process does not appear to discriminate against applicants from lower socioeconomic groups. However, ethnicity, type of (high) school attended, being from an area of high educational participation and (UK) country of medical qualification are strong predictors of allocation to preferred choices. The data provide supportive evidence for the fairness of the allocation process but highlight some interesting findings relating to "pushpull' factors in medical careers decision-making. These findings should be considered when designing postgraduate training policy since this is an important stage of the trainee doctors' working careers. In particular, policy initiatives could focus on the benefits of training at a local foundation school.

Acknowledgements We are grateful to UKMED for releasing the data for this project. We also are grateful to the following for their support of the application to UKMED for this and other research projects: Sally Curtis (University of Southampton, UK), Sandra Nicholson (Barts and The London School of Medicine and Dentistry, UK), PWJ (NHS Education for Scotland, UK) and Rhoda MacKenzie (University of Aberdeen, UK). We thank Daniel Smith and Andy Knapton of the General Medical Council of the UK for their support for the application and throughout the project, particularly regarding data linkage and troubleshooting.

Contributors JAC led the funding bid which was reviewed by KW, BK and PWJ. KW and PWJ advised on the nature of the data. BK managed the data, carried out the data analysis under the supervision of GJP and JAC, and wrote the first manuscript. GJP advised on all the statistical analysis. JAC guided the first draft of the introduction and discussion sections of this paper. BK and GJP wrote the first drafts of the methods and results sections. JAC edited the drafts. All authors reviewed and agreed on the final draft of the paper.

Funding This study is part of BK's doctoral programme of research funded by the UKCAT Research Panel, of which JAC is a member.

Competing interests KW is the special advisor (Recruitment) for the UK's Foundation Programme (UKFPO).

Patient consent Not required.

Ethics approval The Chair of the local ethics committee ruled that formal ethical approval was not required for this study given the fully anonymised data was held in safe haven, and all students who sit UKCAT and GAMSAT are informed that their data and results will be used in educational research. All students applying for the UKFPO also sign a statement confirming that their data may be used anonymously for research purposes. No patients or the general public were involved in this research.

Provenance and peer review Not commissioned; externally peer reviewed.

Data sharing statement UK Medical Education Database (UKMED) UKMEDP 026 extract generated on 12 August 2016. Approved for publication on 27 March 2017. UKMED bears no responsibility for data analysis or interpretation. The dataset is held in safe haven and only members of the research, BK, GP and JC had access to the data. The data include information derived from that collected by the Higher Education Statistics Agency Limited (HESA) and provided to the GMC (HESA Data). Source: HESA Student Record 2007/2008 and 2008/2009 Copyright Higher Education Statistics Agency. The Higher Education Statistics Agency makes no warranty as to the accuracy of the HESA Data, cannot accept responsibility for any inferences or conclusions derived by third parties from data or other information supplied by it.

Open access This is an open access article distributed in accordance with the Creative Commons Attribution Non Commercial (CC BY-NC 4.0) license, which permits others to distribute, remix, adapt, build upon this work non-commercially, and license their derivative works on different terms, provided the original work is properly cited and the use is non-commercial. See: http://creativecommons.org/ licenses/by-nc/4.0/

C Article author(s) (or their employer(s) unless otherwise stated in the text of the article) 2018. All rights reserved. No commercial use is permitted unless otherwise expressly granted.

\section{REFERENCES}

1. Searle J. Equal opportunity does not produce equity: (not) getting into medical school. Med Educ 2003;37:290-1.

2. Young ME, Razack S, Hanson MD, et al. Calling for a broader conceptualization of diversity: surface and deep diversity in four Canadian medical schools. Acad Med 2012;87:1501-10.

3. Southgate E, Kelly BJ, Symonds IM. Disadvantage and the 'capacity to aspire' to medical school. Med Educ 2015;49:73-83.

4. Alexander K, Fahey Palma T, Nicholson S, et al. 'Why not you?' Discourses of widening access on UK medical school websites. Med Educ 2017;51:598-611.

5. Recommendations to the National Center for Education Statistics. Improving the Measurement of Socioeconomic Status for the National Assessment of Educational Progress: A THEORETICAL 
FOUNDATION. 2012 https://nces.ed.gov/nationsreportcard/pdf/ researchcenter/Socioeconomic_Factors.pdf.

6. Independent Reviewer on Social Mobility and Child Poverty. Fair Access to Professional Careers. London: Cabinet Office, 2012.

7. Griffin B, Hu W. The interaction of socio-economic status and gender in widening participation in medicine. Med Educ 2015;49:103-13.

8. Hofmeister M, Lockyer J, Crutcher R. The multiple mini-interview for selection of international medical graduates into family medicine residency education. Med Educ 2009;43:573-9.

9. Dewhurst NG, McManus C, Mollon J, et al. Performance in the MRCP(UK) Examination 2003-4: analysis of pass rates of UK graduates in relation to self-declared ethnicity and gender. BMC Med 2007;5:8.

10. Woolf K, Potts HW, McManus IC. Ethnicity and academic performance in UK trained doctors and medical students: systematic review and meta-analysis. BMJ 2011;342:d901.

11. Roberts JH, Sanders T, Mann K, et al. Institutional marginalisation and student resistance: barriers to learning about culture, race and ethnicity. Adv Health Sci Educ Theory Pract 2010;15:559-71.

12. Humphrey C, Hickman S, Gulliford MC. Place of medical qualification and outcomes of UK General Medical Council "fitness to practise" process: cohort study. BMJ 2011;342:d1817.

13. Foundation Programme 2016 Recruitment Stats and Facts. Interim Report March 2016: UKFPO, 2017. http://www. foundationprogramme.nhs.uk/download.asp?file=stats_and_facts fp2016_interim_report_april_2016_v4.pdf

14. Medical Schools Council. Improving Selection to the Foundation Programme: Final report. ISF Project Group 2011.

15. Archer $L$. inequalities and higher education. In: Archer L, Hutchings M, Ross A, Higher Education and Social Class: Issues of Exclusion and Inclusions. London: Routledge Falmer, 2003:175-91.

16. Nicholson JA, Cleland J, Lemon J, et al. Why medical students choose not to carry out an intercalated BSc: a questionnaire study. BMC Med Educ 2010;10:6.

17. Mahesan N, Crichton S, Sewell H, et al. The effect of an intercalated BSc on subsequent academic performance. BMC Med Educ 2011;11:9.

18. Lumb A, Murdoch-Eaton D. Electives in undergraduate medical education: AMEE Guide No. 88. Med Teach 2014;36:557-72.

19. McManus IC, Dewberry C, Nicholson S, et al. The UKCAT-12 study: educational attainment, aptitude test performance, demographic and socio-economic contextual factors as predictors of first year outcome in a cross-sectional collaborative study of $12 \mathrm{UK}$ medical schools. BMC Med 2013;11:244.

20. Mathers J, Sitch A, Marsh JL, et al. Widening access to medical education for under-represented socioeconomic groups: population based cross sectional analysis of UK data, 2002-6. BMJ 2011;342:d918.

21. Higher Education Funding Council for England (HEFCE). Widening participation and fair access research strategy consultation document: Bristol, 2004.

22. Higher Education Funding Council for England (HEFCE). Young participation in higher educationResearch report: Bristol, 2015.

23. UKFP. Applicants' Handbook: UKFPO, 2018. http://www. foundationprogramme.nhs.uk/pages/home

24. Razack S, Hodges $B$, Steinert $Y$, et al. Seeking inclusion in an exclusive process: discourses of medical school student selection. Med Educ 2015;49:36-47.

25. Nicholson S, Cleland JA. "It's making contacts": notions of social capital and implications for widening access to medical education. Advances in Health Sciences Education 2016:1-14.
26. Senf JH, Campos-Outcalt D, Kutob R. Factors related to the choice of family medicine: a reassessment and literature review. J Am Board Fam Pract 2003;16:502-12.

27. Dowell J, Norbury M, Steven K, et al. Widening access to medicine may improve general practitioner recruitment in deprived and rural communities: survey of GP origins and current place of work. BMC Med Educ 2015;15:165.

28. Lepièce $B$, Reynaert $C$, van Meerbeeck $P$, et al. Social dominance theory and medical specialty choice. Adv Health Sci Educ Theory Pract 2016;21:79-92.

29. General Medical Council. The state of medical education and practice in the UK: 2014. 2014 http://www.gmc-uk.org/SoMEP chapter_1.pdf_58055940.pdf.

30. Cleland JA, Johnston P, Watson V, et al. What do UK medical students value most in their careers? A discrete choice experiment. Med Educ 2017;51:839-51.

31. Goldacre M, Davidson J, Maisonneuve J, et al. Geographical movement of doctors from education to training and eventual career post: UK cohort studies. J R Soc Med 2013;106:96-104.

32. Cleland J, Johnston P, Watson V, et al. What do UK doctors in training value in a post? A discrete choice experiment. Med Educ 2016;50:189-202.

33. Singleton AD. Educational Opportunity The Geography of Access to Higher Education. Ashgate Publishing Ltd: Farnham: Farnham, 2010.

34. Independent Schools Council. CENSUS AND ANNUAL REPORT. 2017 https://www.isc.co.uk/media/4069/isc-census-2017-final.pdf

35. Scrimgeour D, Cleland J, Lee AJ, et al. Predictors of success in the Intercollegiate Membership of the Royal College of Surgeons (MRCS) examination. Ann R Coll Surg Engl 2018;104:43.

36. UK Medical Education Database. https://www.ukmed.ac.uk/

37. MacKenzie RK, Cleland JA, Ayansina D, et al. Does the UKCAT predict performance on exit from medical school? A national cohort study. BMJ Open 2016;6:e011313.

38. Kumwenda B, Cleland JA, Walker K, et al. The relationship between school type and academic performance at medical school: a national, multi-cohort study. BMJ Open 2017;7:e016291.

39. Gillborn D, Safia Mirza H. MAPPING RACE, CLASS AND GENDER A synthesis of research evidence. London: Office for Standards in Education, 2000. http://dera.ioe.ac.uk/4428/2/Educational_ inequality_mapping_race,_class_and_gender_\%28PDF_format\%29. pdf

40. Garner S, Poverty BG. ethnicity and place. York: The Joseph Rowntree Foundation (JRF), 2011. https://www.jrf.org.uk/sites/ default/files/jrf/migrated/files/poverty-ethnicity-place-full.pdf

41. Mangan J, Hughes A, Davies P, et al. Fair access, achievement and geography: explaining the association between social class and students' choice of university. Studies in Higher Education 2010;35:335-50.

42. Reay D, Ball S, David M E. Degrees of Choice: Social Class, Race and Gender in Higher Education. Stoke-on-Trent: Institute of Education Press, 2005.

43. Steven K, Dowell J, Jackson C, et al. Fair access to medicine? Retrospective analysis of UK medical schools application data 20092012 using three measures of socioeconomic status. BMC Med Educ 2016;16:10.

44. Cousans F, Patterson F, Edwards $\mathrm{H}$, et al. Evaluating the complementary roles of an SJT and academic assessment for entry into clinical practice. Adv Health Sci Educ Theory Pract 2017:22:401-13

45. Petty-Saphon K, Walker K, Patterson F, et al. Situational judgment tests reliably measure professional attributes important for clinical practice. Advances in medical education and practice 2017;8:21-3. 